\title{
Marc-doa for Cognitive and Psychomotor Learning: Preliminary Design and Evaluation
}

\author{
Hendra Pradibta ${ }^{1 *}$, Usman Nurhasan ${ }^{2}$ \\ 1,2 Department of Information Technology, Politeknik Negeri Malang, East Jawa, Indonesia \\ Corresponding author: * hendra.pradibta@polinema.ac.id \\ Received Date: 29 April 2021 \\ Accepted Date: 27 May 2021 \\ Published Date: 1 September 2021
}

HIGHLIGHTS

- Mobile augmented reality cognitive prayer (Marc-doa) can be used as an alternative media for learning daily prayers for children

- Marc-doa can complement conventional text-based learning with interactive learning using tangible cube markers.

- Marc-doa can support learning in both cognitive and psychomotor aspects

\begin{abstract}
Marc-doa application is Mobile Augmented Reality cubes used as a learning media for children, focusing on cognitive and psychomotor learning. The contents of this application are daily prayers for Muslim children and designed in the form of audio-video animations. The development of the Marc-doa application uses the Multimedia Development Life Cycle method. This research aims to discuss the design and evaluation of Marc-doa. Evaluation and technical tests are conducted on several aspects, specifically on the detection process, distance, angle, and surface area. In addition, the testing process is to identify the ideal conditions for the use of Marc-doa. From the evaluation and testing process, four markers showed good results. Only one marker does not show the results as expected. The ideal distance for using Marc-doa application between $25-40 \mathrm{~cm}$. The angle for ideal reception between 0-30 degrees and the surface area Marc-doa application can detect markers correctly between 50\%-100\% surface area. The ideal distance, surface area, and conditions for utilising Marc-doa application were obtained from this research.
\end{abstract}

Keywords: Mobile Augmented Reality, Cognitive, Psychomotor, Learning Media.

\section{INTRODUCTION}

Technology has experienced rapid development in the last two decades (Chen, Liu, Cheng, \& Huang, 2017), and has contributed to every aspect of life, including education. Technology has changed the way people learn and gather information. Also, conventional learning processes have become more interesting with the presence of technology (Kokkalia \& Drigas, 2016). As one example, some start-ups combine technology with education; one of the start-ups is Ruangguru. Ruangguru introduces online learning services for students from elementary to high school (Techninasia, 2017). By utilising mobile technology, Ruangguru can create an interactive and fun learning process. Ruangguru can expand access to a good quality of education in various regions in Indonesia. Local start-ups in the fields of educational 
technology that offer similar services include Kelase (Kelase, 2018), Zenius (Zenius, 2018), and Quipper (Quipper, 2018).

Based on its purpose, education is not only for developing brain functions but also for developing other abilities. According to Bloom in Armstrong (Armstrong, 2016), there are three classifications or aspects in the learning domain, i.e., cognitive, affective and psychomotor aspects. Cognitive aspects include the field of brain activity, such as thinking, memorising, and evaluating. Affective aspects cover the domain of behaviour, emotions, and values. While for psychomotor aspects, it is more on skills that focus on physical activity involving muscles, eyes and hand coordination. The physical activity can be arranging blocks, playing puzzles, cutting, sticking and colouring.

In this research, a mobile application augmented reality cubes (Marc-doa) was developed as an alternative learning media by utilising Augmented Reality (AR) technology (Pradibta, 2018). AR is a technology that combines virtual objects in the form of text, images, and animations into the real world (Azuma, 1997), (Meni et al., 2018). AR has great potential in attracting, inspiring, and motivating users to explore and control from a variety of different perspectives (Lee, 2012), (Pradibta, Wijaya, Ronilaya, \& Nurhasan, 2018), (Pradibta \& Wijaya, 2017).

Marc-doa combines AR with tangible cubes. Marc-doa application refers to the CogArC application (Boletsis \& Mccallum, 2014), (Boletsis \& McCallum, 2016a), (Boletsis \& McCallum, 2016b), which uses the interaction of AR-based technology and manipulation of tangible objects. Marc-doa includes the content of the Muslim daily prayers in the form of video audio animation. The purpose of developing Marc-doa is to provide an attractive alternative learning media and have the ability to train children's cognitive and psychomotor aspects.

This research aims to contribute to the field of learning and education by providing alternative learning media other than textbooks. Together with the physical activity of arranging cubes, users can practice cognitive and psychomotor skills simultaneously. Furthermore, this research will contribute to the use of AR with the interaction of physical objects in the form of cubes, design development, and the process of technical testing perform in the development process.

\section{RELATED WORKS}

Many studies have shown that augmented reality technology effectively produces something interesting and interactive in the learning process. Clark and Dunser (Clark \& Dünser, 2012)create books that combine colouring activities with three dimensional (3D) content. In this research, a colouring book can display images in $3 \mathrm{D}$, according to the colours given by the user. With the presence of 3D content, users get other experiences in the learning process. AR in the form of books can help readers interact with the content contained in the book to be easier to understand the learning material.

Augmented Reality in Medical Education (Kamphuis, Barsom, Schijven, \& Christoph, 2014), Kamphuis discusses educational technology, especially AR technology, which has great potential to support the learning process of medical education. AR can combine virtual content in the real world, wherein the reallife contexts cannot always be done due to several limitations. This study discusses three AR applications that focus on health education, visualising human anatomical structure with AR, Visualising 3D lung dynamics with AR, and Laparoscopic skills training with AR

Augmenting child reality: Using Educational Tablet Technology (Tanner, Karas, \& Schofield, 2014), Tanner observes the process of teaching and learning with the use of augmented reality. The learning process using augmented reality has shown the ability of AR to provide clear information and instructions 
to students in completing tasks. The learning process here is giving instructions to make a Lego robot in the form of audio-video animation. A different approach is made by giving instructions in the form of a manual handbook. The results obtained differences between students who work using manual handbook compared to using AR animation. Students who work on tasks with AR animation show better results than students who work with a manual handbook

How do young children engage with mobile apps? Cognitive, Psychomotor, and Affective Perspective (Noorhidawati, Ghalebandi, \& Hajar, 2015), This study emphasises the conditions under which mobile apps can improve children's understanding of the learning process. Research conducted by Noorhidawati, indicating that the learning process conditions utilising mobile apps can provide learning experiences in three aspects of learning domains, cognitive, psychomotor and affective.

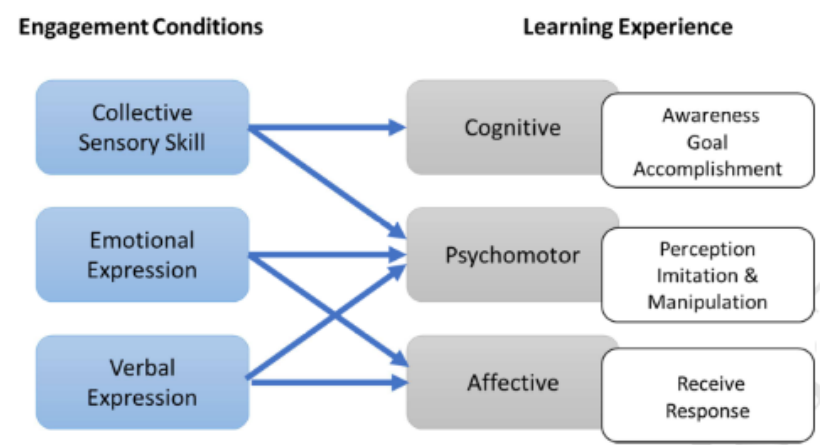

Figure 1: Engagement conditions of children's learning when interacting with mobile apps

The next research is CogARC, A serious game for cognitive training (Boletsis \& McCallum, 2016b). CogARC is a serious game for cognitive training and screening, utilising interaction techniques based on augmented reality and manipulation of real physical objects in the form of cubes. This app is designed for the elderly, players with mild cognitive impairment, and healthy adults interested in games and or cognitive training. The purpose of this application is to alleviate or prevent cognitive decline.

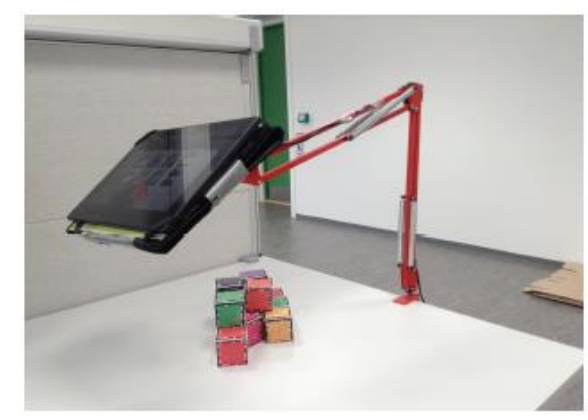

Figure 2: $\operatorname{Cog} A R C$ interaction settings: 10 cubes and a tablet $P C$ on the base stand.

Based on several research papers above, it can be concluded that AR and learning are an exciting combination in the education area. Students need media that can interest or attract them to learn and play and provide a learning experience that differs from a conventional learning method. Hence, this research proposes an application which is combining AR technology and tangible cube marker as an alternative learning media. As stated earlier in the introduction, this current research referring to the research conducted by Boletsis, who developed the Cognitive Augmented Reality Cubes (CogARC) application. 


\section{METHODOLOGY}

Marc-doa development utilises the Multimedia Development Life Cycle approach, which consists of 6 stages. These stages are concepts, designs, material collecting, assembly, testing, and distribution (Luther, 1994), (Sutopo, 2011), (Sutopo \& Pamungkas, 2017).

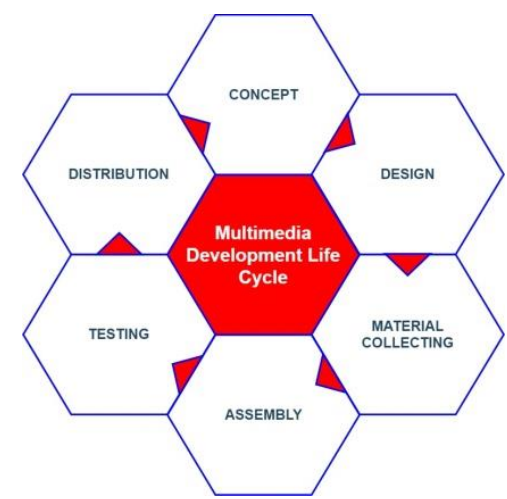

Figure 3: Multimedia Development Life Cycle

Marc-doa is designed to develop cognitive and psychomotor abilities for children. The cognitive aspect of this application is the knowledge of daily prayers. As for psychomotor abilities, Marc-doa requires users to construct cube markers. The users have to arrange the cubes marker correctly to display the content.

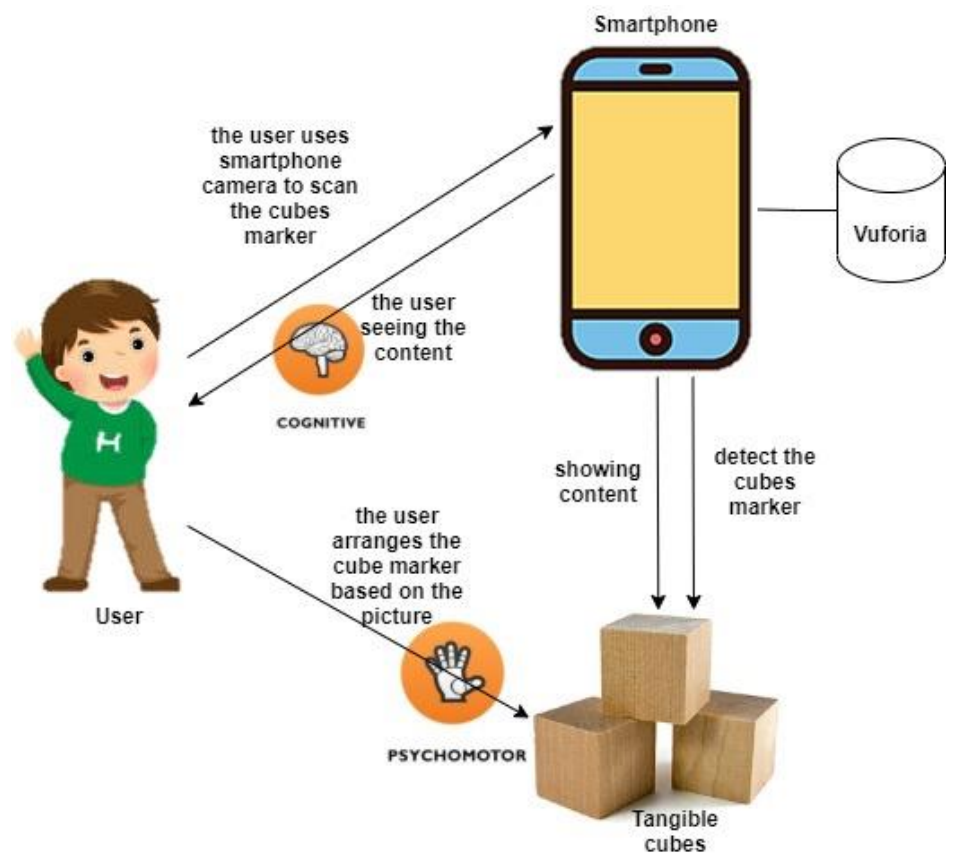

Figure 4: Marc-doa framework

\section{FINDINGS AND DISCUSSIONS}

Findings and discussions of the research fall into describing five stages from 6 stages in the MDLC approach (distribution not included). Evaluation just has been conducted for the testing stage during the 
development process. Implementation phases are not performed in this research, and it will be conducted in future research.

\section{Concept}

The main concept of Marc-doa is a learning media that combines AR technology with tangible cubes. Tangible cubes are used as a marker to display animated video audio content. The markers will be formed in a puzzle model, and this concept developed as part of increasing user experience with learning media

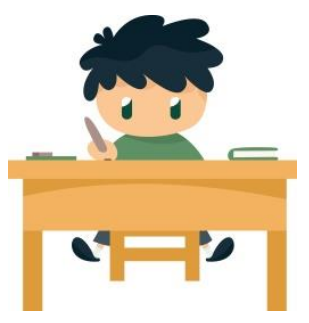

Character 1

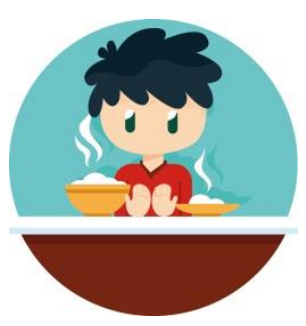

Character 4

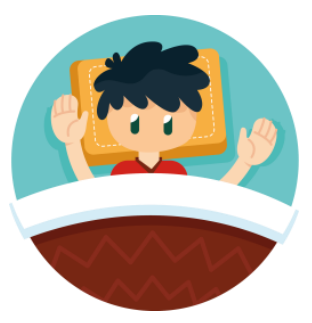

Character 2

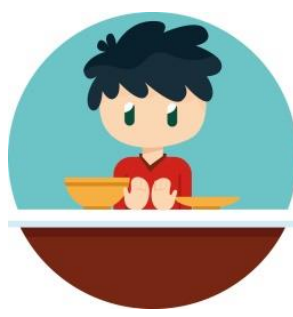

Character 5

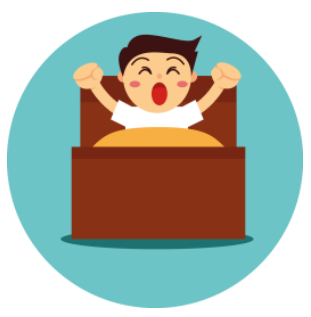

Character 3

Figure 5: Marc-doa Characters

\section{Design}

In general, the use of the Marc-doa application is illustrated in Figure 4. In the first step, the user is given four marker cubes where each cube has $1 / 4$ part of the whole image (Figure 5 dan Figure 6 ). In the second step, the user must set 4 random cubes into complete and perfect character images (Figure 5). In the third step, the user opens the Marc-doa application and directs the camera to the cube arrangement that has been made. When the cube is arranged to form a perfect image, Marc-doa display animated audio-video content that matches the marker. 


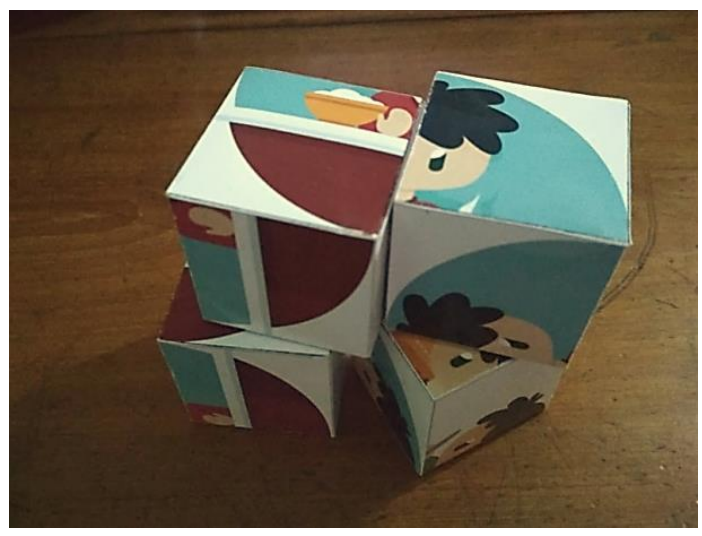

Figure 6: Marc-doa Cubes

\section{Material Collecting}

The material collection is done as part of content creation. Materials needed include daily audio prayer, Arabic and Latin writing from daily prayers. The materials needed in developing this application were obtained from several sources on the internet by making several modifications. The Making animated content using Adobe Photoshop and Adobe After Effects applications

\section{Assembly}

The assembly stage is done for the process of developing the Marc-doa application. The final application is built in the form of an android application (.apk). The development of Marc-doa utilises Unity and Vuforia application.

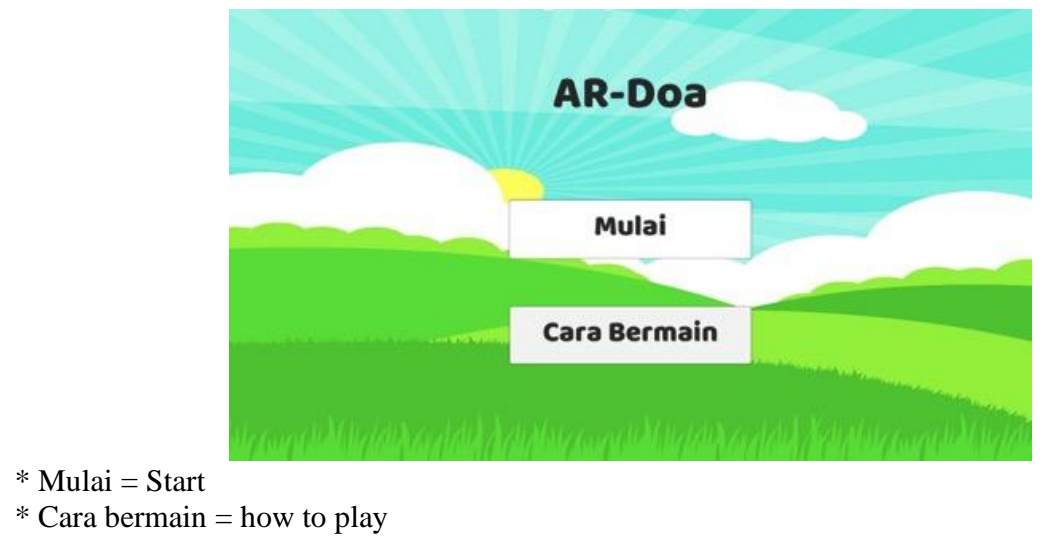

Figure 7: Marc-doa Application

\section{Testing}

The testing process is done using Xioami Redmi 4x smartphone. The first test is distance testing. Distance testing is done to determine the ideal distance range in the use of Marc-doa. The testing process is shown in Figure 8 and Figure 9. 

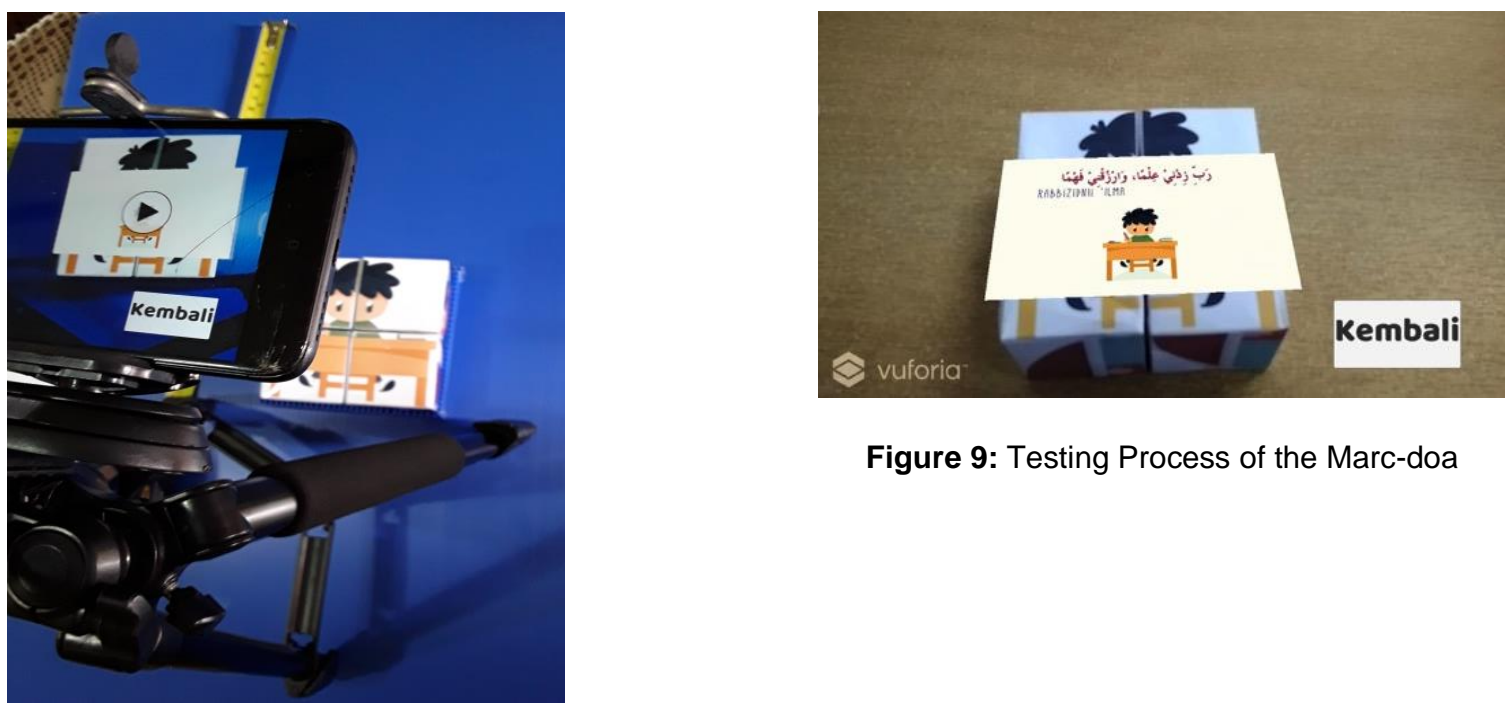

Figure 9: Testing Process of the Marc-doa

Figure 8: Testing Process of the Marc-doa

As can be seen in Figure 7 and Figure 8, the testing scenario is carried out by placing the smartphone on a tripod. The distance between the tripod and the marker cubes has been adjusted, so the smartphone cannot detect the marker. Afterwards, the distance changes gradually until the content can appear perfectly. Distance testing is performed to find the optimal distance for the application to recognise the markers and indicate their contents. The results are shown in Table 1.

Table 1: Distance Testing

\begin{tabular}{l|c|c|c|c|c|c|c|c|c|}
$\begin{array}{l}\text { Markers } \\
\text { Number }\end{array}$ & \multicolumn{70}{c|}{ Test results distances } \\
& 5 & 10 & 15 & 20 & 25 & 30 & 35 & 40 & 45 \\
\hline $\mathbf{1}$ & FALSE & FALSE & FALSE & FALSE & TRUE & TRUE & TRUE & TRUE & FALSE \\
\hline $\mathbf{2}$ & FALSE & FALSE & FALSE & FALSE & TRUE & TRUE & TRUE & TRUE & FALSE \\
\hline $\mathbf{3}$ & FALSE & FALSE & FALSE & FALSE & TRUE & TRUE & TRUE & TRUE & FALSE \\
\hline $\mathbf{4}$ & FALSE & FALSE & FALSE & FALSE & TRUE & TRUE & TRUE & TRUE & FALSE \\
\hline $\mathbf{5}$ & FALSE & FALSE & FALSE & FALSE & TRUE & TRUE & TRUE & TRUE & FALSE \\
\hline
\end{tabular}

$*$ True $=$ animated content can be detected

$*$ False $=$ animated content cannot be detected

The distance test uses a 0-degree angle to the cube marker. The following process is to change the tripod position. The results showed that Marc-doa could detect markers at an angle of 0-29 degrees. In addition, testing shows that above 30 degrees, Marc-doa cannot detect the cube marker. The testing process for detecting the cube marker runs according to the design and concept. Of the five markers, Marc-doa can detect four markers correctly. One marker cannot display the content according to the design created. Marker detection does not take long, and the average detection time is between two-three seconds. Area marker testing is done by replacing one of the cubes, resulting in an incomplete marker image. When Marc-doa can detect the cube marker and display its contents, the test is assumed to be successful. The test results are presented in Table 2. 
Table 2: Marker Area Testing

\begin{tabular}{|c|c|c|c|c|}
\hline $\begin{array}{c}\text { Markers } \\
\text { number }\end{array}$ & \multicolumn{4}{c|}{ Marker Area } \\
\hline & $25 \%$ & $50 \%$ & $75 \%$ & $100 \%$ \\
\hline $\mathbf{1}$ & FALSE & TRUE & TRUE & TRUE \\
\hline $\mathbf{2}$ & FALSE & TRUE & TRUE & TRUE \\
\hline $\mathbf{3}$ & FALSE & TRUE & TRUE & TRUE \\
\hline $\mathbf{4}$ & FALSE & TRUE & TRUE & TRUE \\
\hline $\mathbf{5}$ & FALSE & TRUE & TRUE & TRUE \\
\hline
\end{tabular}

$*$ True $=$ animated content can be detected

*False $=$ animated content cannot be detected

The testing process was carried out according to Marc-doa's requirements. Of the five testing processes, four tests showed results that were in line with expectations. Only one testing process needs to be improved. The detection process on the marker shows unsatisfactory results. Marc-doa returns content that does not match the cube marker. This condition occurs because the markers have a high degree of similarity (character 4 and character 5) in Figure 10 and Figure 12. Improvements that can be made are to create a new cube marker design that is different from other markers. The test results are presented in Table 3.

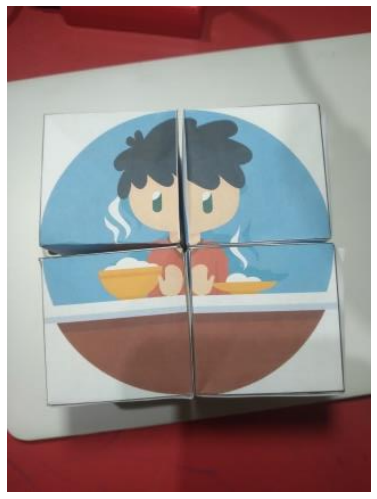

Figure 10: Character 4 cubes

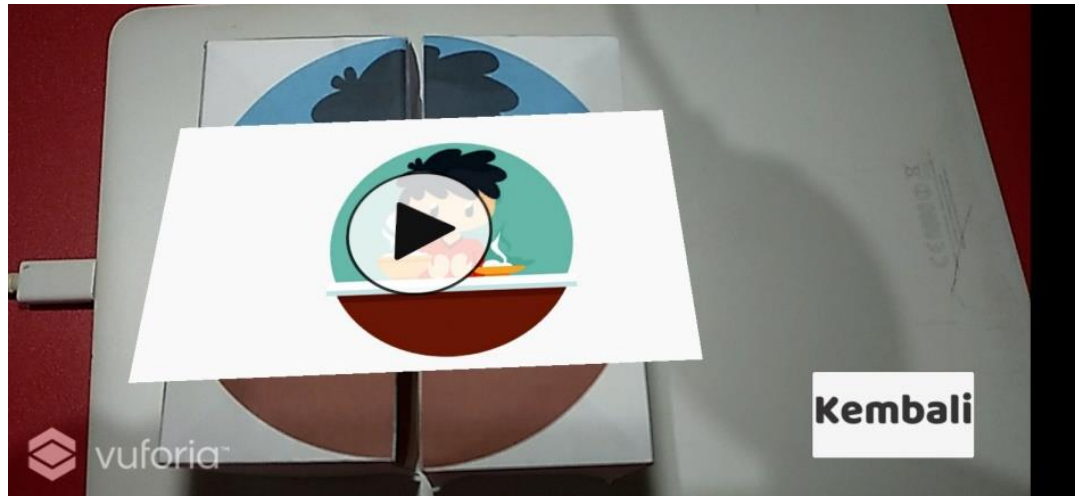

Figure 11: Content for character 4

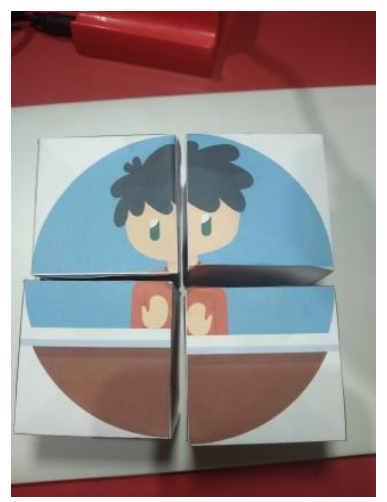

Figure 12: Character 5 cubes 


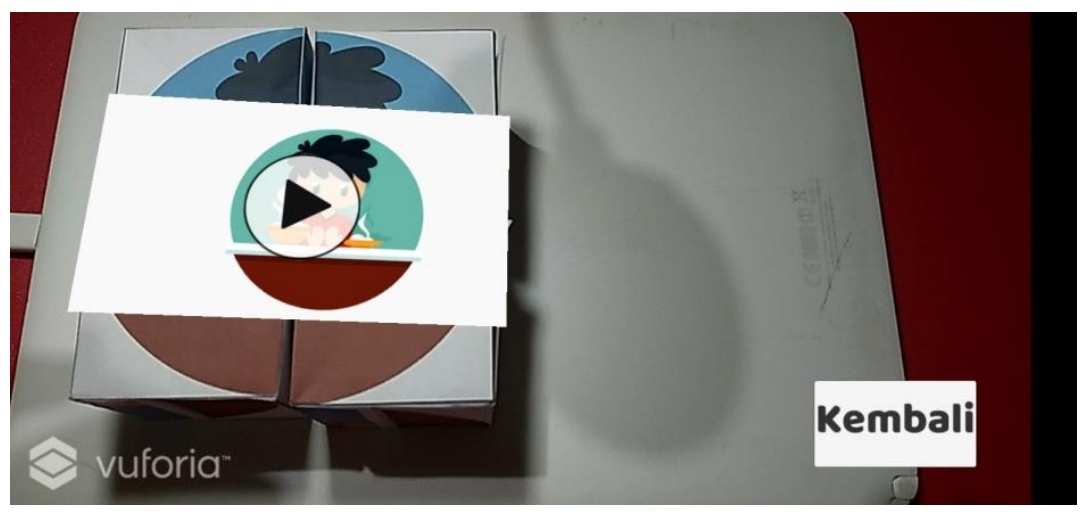

Figure 13: Character 5 shows content for Character 4

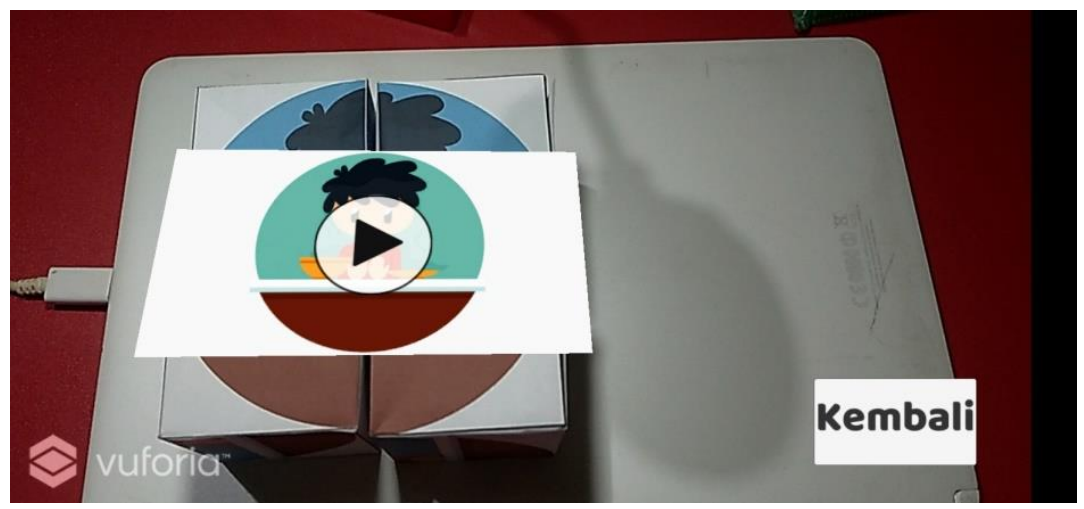

Figure 14: Content for character 5

Table 3: Marker Testing Results

\begin{tabular}{|c|l|}
\hline Character & \multicolumn{1}{|c|}{ Results (content) } \\
\hline $\mathbf{1}$ & The marker shows the matched content \\
\hline $\mathbf{2}$ & The marker shows the matched content \\
\hline $\mathbf{3}$ & The marker shows the matched content \\
\hline $\mathbf{4}$ & The marker shows the matched content (Figure 11) \\
\hline $\mathbf{5}$ & Sometimes display mismatched content (Figure 13 \& Figure 14) \\
\hline
\end{tabular}

\section{CONCLUSION AND RECOMMENDATIONS}

Based on the research that has been done, it can be concluded that Marc-doa can work well following the concepts and designs that have been made. Markers can be detected precisely and can display the appropriate content. Several problems with marker detection have been identified, and solutions can be obtained. Marc-doa can support learning in both cognitive and psychomotor aspects. In addition, Marcdoa can complement conventional text-based learning with interactive learning using tangible cube markers. The following research is to implement and test to target users, and it is expected to show positive results. The use of Marc-doa as an alternative medium for cognitive and psychomotor learning needs further investigation. The focus of the research is the use of Marc-doa for early childhood education. 


\section{ACKNOWLEDGMENTS}

The authors would like to thank the Indonesian Ministry of Education and Culture (Kemendikbud) and Politeknik Negeri Malang (Polinema), East Jawa, who have supported this research project.

\section{REFERENCES}

Armstrong, P. (2016). Bloom's taxonomy. Vanderbilt University Center for Teaching.

Azuma, R. (1997). A survey of augmented reality. Presence: Teleoperators and Virtual Environments, 6(4), 355-385. https://doi.org/10.1.1.30.4999

Boletsis, C., \& Mccallum, S. (2014). Augmented reality cube game for cognitive training: an interaction study. Studies in Health Technology and Informatics, 200, 81-87.

Boletsis, C., \& McCallum, S. (2016a). Augmented Reality Cubes for Cognitive Gaming: Preliminary Usability and Game Experience Testing. International Journal of Serious Games, 3(1), 3-18. https://doi.org/10.17083/ijsg.v3i1.106

Boletsis, C., \& McCallum, S. (2016b). Smartkuber: a serious game for cognitive health screening of elderly players. Games for Health Journal, 5(4), 241-251.

Chen, P., Liu, X., Cheng, W., \& Huang, R. (2017). A review of using Augmented Reality in Education from 2011 to 2016. In Innovations in Smart Learning (pp. 13-18). Springer.

Clark, A., \& Dünser, A. (2012). An interactive augmented reality coloring book. IEEE Symposium on 3D User Interfaces 2012, 3DUI 2012 - Proceedings, (October), 7-10. https://doi.org/10.1109/3DUI.2012.6184168

Kamphuis, C., Barsom, E., Schijven, M., \& Christoph, N. (2014). Augmented Reality in Medical Education? Perspectives on Medical Education, 3(4), 300-311.

Kelase. (2018). Kelase. Retrieved October 23, 2018, from https://www.kelase.net/

Kokkalia, G. K., \& Drigas, A. S. (2016). Mobile Learning for Special Preschool Education. International Journal of Interactive Mobile Technologies (IJIM), 10(1), 60-67.

Lee, K. (2012). Augmented Reality in Education and Training. Linking Research and Practice to Improve Learning, 56(2), 13-21. https://doi.org/10.1007/s11528-012-0559-3

Luther, A. C. (1994). Authoring Interactive Multimedia (The IBM Tools Series). AP Professional.

Meni, V., Boonbrahm, P., Kaewrat, C., Pengkaew, P., Boonbrahm, S., \& Meni, V. (2018). Study of the Hand Anatomy Using Real Hand and Augmented Reality. International Journal of Interactive Mobile Technologies (IJIM), 12(7), 181-190. 
Noorhidawati, A., Ghalebandi, S. G., \& Hajar, R. S. (2015). How Do Young Children Engage with Mobile Apps? Cognitive, Psychomotor, and Affective Perspective. Computers \& Education. https://doi.org/10.1016/j.compedu.2015.07.005.

Pradibta, H. (2018). Augmented Reality : Daily Prayers for Preschooler Student. International Journal of Interactive Mobile Technologies, 12(1), 151-159. https://doi.org/10.3991/ijim.v12i1.7269.

Pradibta, H. \& Wijaya, I. D. (2017). Designing AR Daily Prayers for Children with ASD. In Application for Technology of Information and Communication (iSemantic), 2017 International Seminar on (pp. 100-103). Semarang. https://doi.org/10.1109/ISEMANTIC.2017.8251851.

Pradibta, H., Wijaya, I. D., Ronilaya, F., \& Nurhasan, U. (2018). The evaluation on a mobile augmented reality application as therapy media. In MATEC Web of Conferences (Vol. 197, p. 15004).

Quipper. (2018). Quipper. Retrieved October 23, 2018, from https://www.quipper.com/id/video/.

Sutopo, H. (2011). Selection Sorting Algorithm Visualization. The International Journal of Multimedia \& Its Applications, 3(1), 22-35.

Sutopo, H., \& Pamungkas, W. (2017). Developing Mathematics Mobile Game to Enhance Learning for Children. In Computational Science and Engineering (CSE) and Embedded and Ubiquitous Computing (EUC), 2017 IEEE International Conference on (Vol. 1, pp. 191-197).

Tanner, P., Karas, C., \& Schofield, D. (2014). Augmenting a Child's Reality : Using Educational Tablet Technology. Journal of Information Technology Education: Innovations in Practice, 13, 45-54.

Techninasia. (2017). Ruangguru Perkenalkan Layanan Ruangbelajar Sebagai Alternatif Bimbel. Retrieved October 22, 2018, from https://id.techinasia.com/ruangguru-perkenalkan-layanan-ruangbelajaralternatif-bimbel.

Zenius. (2018). Zenius. Retrieved October 23, 2018, from https://www.zenius.net/about 